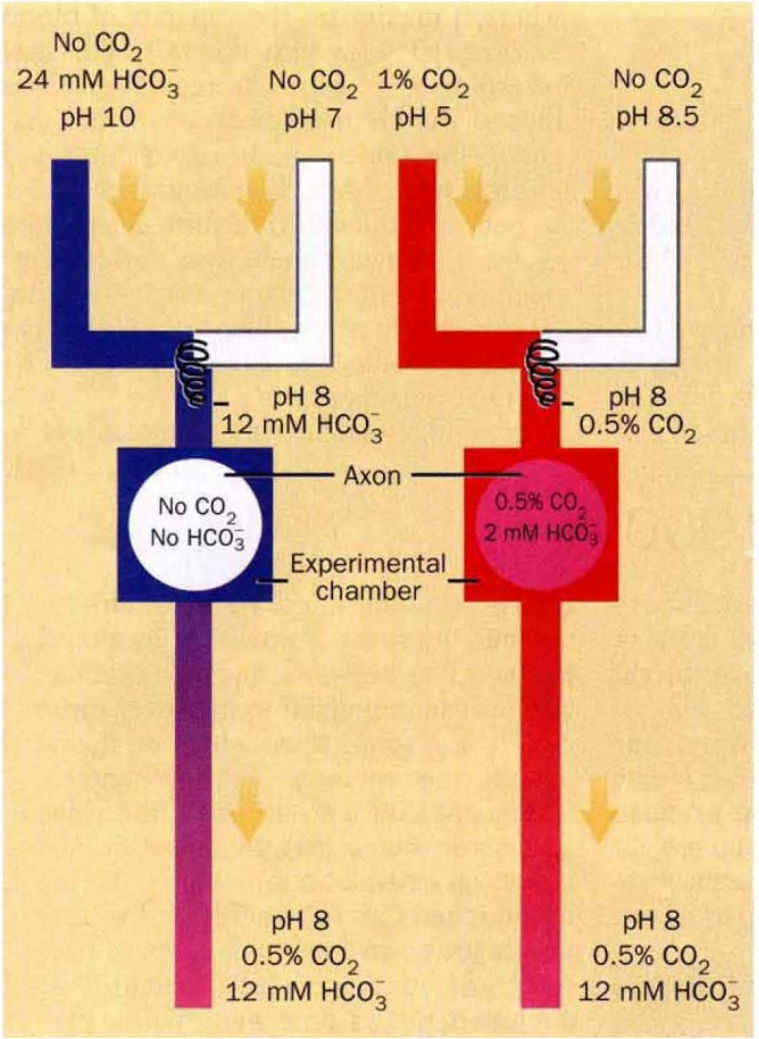

The continuous-flow apparatus and technique employed by Zhao et al. ${ }^{1}$ to discover the $\mathrm{KHCO}_{3}^{-}$cotransporter. The significance of the work lies not so much in the cotransporter, the physiological function of which is not known, as in the imaginative experimental protocol involving out-ofequilibrium solutions.

squid giant axons ${ }^{6}$ but bicarbonate is still carried across the axon membrane in the complete absence of $\mathrm{Na}^{+}$or $\mathrm{Cl}^{-}$ions ${ }^{1}$. It proved difficult to investigate the mechanism involved using conventional $\mathrm{CO}_{2} /$ $\mathrm{HCO}_{3}^{-}$solutions, because the $\mathrm{CO}_{2}$ makes it impossible to maintain a significant bicarbonate gradient. The normal bicarbonate saline of $\mathrm{pH} 8$ used in squid-axon experiments contains $12 \mathrm{mM}$ bicarbonate and must be equilibrated with $0.5 \% \mathrm{CO}_{2}$ to be stable. If this equilibrium is disturbed, for example by the loss of $\mathrm{CO}_{2}$ to the atmosphere, the $\mathrm{pH}$ will slowly increase as bicarbonate too is converted to $\mathrm{CO}_{2}$ and lost.

A stable bicarbonate solution must therefore contain $\mathrm{CO}_{2}$. This crosses cell membranes so fast that its level inside cells is only rarely different from that outside. The intracellular $\mathrm{CO}_{2}$ is in equilibrium with intracellular $\mathrm{H}^{+}$and $\mathrm{HCO}_{3}^{-}$, often catalysed by the almost ubiquitous carbonic anhydrase. So you cannot normally have external bicarbonate without a similar level inside cells. The exact level will depend on the intracellular $\mathrm{pH}$, but this is usually close to the external $\mathrm{pH}$.

Zhao and colleagues ${ }^{1}$ solved the problem by the clever use of out-ofequilibrium solutions (see figure). They mixed two pairs of carefully formulated solutions in a continuous-flow apparatus which delivered the mixture to the outside of a squid axon within half a second. They mixed either a $24 \mathrm{mM}$ bicarbonate alkaline solution or a $1 \% \mathrm{CO}_{2}$ acid solution with acid or alkaline $\mathrm{CO}_{2}$ /bicarbonate-free solutions to give $\mathrm{pH} 8$ mixtures with $12 \mathrm{mM}$ bicarbonate or $0.5 \% \mathrm{CO}_{2}$. The rate constants of the conversion of bicarbonate to $\mathrm{CO}_{2}$ and vice versa are such that very little takes place within half a second. All solutions contained acetazolamide to inhibit any carbonic anhydrase that might be present.

That the $\mathrm{CO}_{2}$-free, freshly mixed solution indeed contained almost no $\mathrm{CO}_{2}$ is shown convincingly by its lack of effect on the intracellular buffering power, which Zhao et al. measured by applying ammonium solutions. The equilibrated $\mathrm{CO}_{2} / \mathrm{HCO}_{3}^{-}$solution increased buffering power by $57 \%$, as expected, whereas the out-of-equilibrium solution increased it by only $7 \%$.

In contrast to its lack of effect on buffering, the $\mathrm{CO}_{2}$-free, out-of-equilibrium bicarbonate solution doubled bicarbonate uptake rates by potassiumdepleted axons in high-K solution, strong evidence for cotransport of $\mathrm{K}$ and $\mathrm{HCO}_{3}^{-}$. Similarly, bicarbonate efflux from Kloaded axons in bicarbonate-free solutions was much faster if the bathing solution contained $\mathrm{CO}_{2}$. The $\mathrm{CO}_{2}$ outside is converted to about $2 \mathrm{mM}$ bicarbonate inside, so there is a large outward bicarbonate gradient as well as $\mathrm{K}$ gradient to drive the cotransporter.

The physiological function of this hitherto unknown $\mathrm{K} / \mathrm{HCO}_{3}^{-}$cotransporter is obscure. But the new technique applied by Zhao et al. may breathe fresh life into the study of bicarbonate transport generally.

Roger C. Thomas is in the Department of Physiology, School of Medical Sciences, University of Bristol, University Walk, Bristol BS8 1TD, UK

1. Zhao, J., Hogan, E. M., Bevensee, M. O. \& Boron, W. F. Nature 374, 636-639 (1995).

2. Maren. T. H. Physiol. Rev. 47, 595-781

(1967)

3. Widdas, W. F. Baker G. F \& Baker P. Crtobios $80,7-24$ (1994)

4. Thomas, R. C. J. Physiol., Lond. 273, 317-338 (1977).

5. Schwiening, C. J. \& Boron, W. F. J. Physiol., Lond. 475, 59-67 (1994)

6. Boron, W. F. \& Russell, J. M. J. gen. Physiol. 81, 373-399 (1983)

\section{Cold melting}

MANY products and components are given their final form by casting or moulding. This fails with refractory ceramics, and also with materials that decompose on heating, such as wood, concrete, textiles, bone and leather. Daedalus is now devising a way of melting anything, simply and safely.

He points out that the molecules in a solid lattice vibrate at the Einstein frequency, which is typically around $10^{12}$ $\mathrm{Hz}$ or so. If you heat a solid, you excite this vibrational mode, which ultimately melts it. Unfortunately, you also excite all the other modes as well, including those that lead to molecular breakdown. The answer is to excite the critical lattice mode on its own. In principle, a farinfrared laser tuned to the Einstein frequency should do the trick. At first Daedalus feared that its energy would be swiftly transferred to the higher, more destructive modes. But he now thinks otherwise. Energy is rapidly shifted from higher to lower modes; but the reverse process is not so easy. Many phosphors absorb ultraviolet and re-emit visible light, but none go the other way. So the far-infrared beam should melt the target 'coldly', without thermal decomposition.

Far-infrared lasers, however, are very hard to tune. DREADCO's chemists are therefore trying a converse strategy. They are doping suitable solids, subjecting them to isotopic substitution and so on, to shift their Einstein frequencies to a given laser line. Irradiated by that line, they should sag and slump to a cool liquid puddle. Switch the laser off, and they should rapidly set, warming slightly as the absorbed energy degrades to heat.

If the idea works, more versatile infrared emitters will be pressed into service: free-electron lasers, SmithPurcell sources and so on. These can be tuned to the Einstein frequencies of useful solids. The results will transform technology. Concrete that can be melted in place and re-set instantly; cupboards, sideboards and grand pianos cast from liquid wood; rococo moulded marble tombstones; seamless drawn leather shoes and coats, and one-piece die-cast leather footballs; paper rolled from sawdust slurry; hamburgers cast from molten meat; all will be possible.

Better still, all these products could be modified, glued, dismantled, recast or recycled by a tuned infrared beam which would cold-melt the target material and leave the rest untouched. Daedalus is now dreaming up an infrared torch to soften the wreckage around trapped crash-victims, and infrared figure reshaping to compete with plastic surgery.

David Jones 